\title{
Development and Validation of a Rapid and Reliable HPLC-FLD Method for the Quantification of Ciprofloxacin and Enrofloxacin Residues in Zea mays
}

\author{
Júlio C. M. Brito, ${ }^{\# a}$ Vinícius Bernardoni,,$\# a$ Thais M. L. da Silva, ${ }^{b}$ \\ Laurenice S. X. S. Ramos, ${ }^{a}$ Marcelo P. Gomes ${ }^{c}$ and Débora C. S. de Assis ${ }^{\circledR *, b}$ \\ ${ }^{a}$ Fundação Ezequiel Dias, Rua Conde Pereira Carneiro, 80, 30510-010 Belo Horizonte-MG, Brazil \\ ${ }^{b}$ Departamento de Tecnologia e Inspeção de Produtos de Origem Animal, Escola de Veterinária, \\ Universidade Federal de Minas Gerais, Av. Antônio Carlos, 6627, CP 567, \\ 30123-970 Belo Horizonte-MG, Brazil \\ 'Departamento de Botânica, Setor de Ciências Biológicas, Universidade Federal do Paraná, \\ Avenida Coronel Francisco H. dos Santos, 100, Centro Politécnico, Jardim das Américas, \\ CP 19031, 81631-980 Curitiba-PR, Brazil
}

\begin{abstract}
The accumulation of antibiotics by plants is a currently concern associated to yield reduction and transference of antibiotic residues along the food web. Maize is a staple food in many parts of the world; it is also considered an important ingredient in animal nutrition. Considering the lack of validated analytical methods for the analysis of ciprofloxacin (CIPRO) and enrofloxacin (ENRO) in the shoot of Zea mays maize, we developed a reliable reversed-phase high-performance liquid chromatography method with fluorescence detection (HPLC-FLD). This method was validated for linearity, matrix effects, precision, accuracy, limits of quantification (LOQ) and detection (LOD), and robustness. The analytical curves were linear with coefficient of determination $\left(\mathrm{R}^{2}\right)$ of 0.9907 for CIPRO and 0.9962 for ENRO. The LOD values were 16.65 and $6.57 \mu \mathrm{g} \mathrm{kg}^{-1}$ for CIPRO and ENRO, respectively, whereas LOQ values were $50.44 \mu \mathrm{g} \mathrm{kg}^{-1}$ (CIPRO) and $19.92 \mu \mathrm{g} \mathrm{kg}^{-1}$ (ENRO). HPLC-FLD also displayed good precision and accuracy. Therefore, the proposed method can be considered a reliable and useful tool for the analysis of ciprofloxacin and enrofloxacin in the shoot of maize.
\end{abstract}

Keywords: maize, residue, ciprofloxacin, enrofloxacin, HPLC-FLD, validation

\section{Introduction}

The use of antibiotics in farming is a common practice to promote animal growth and prevent and treat diseases. ${ }^{1}$ Among antibiotic classes, fluoroquinolones, such as enrofloxacin (ENRO), are often used in animal husbandry. Once administered, ENRO is partially metabolized to ciprofloxacin (CIPRO), its main metabolite. Since the administered antibiotic is not completely assimilated by the organisms, both ENRO and CIPRO are eliminated in animal excrement. Bodies of water are the main sink of antibiotics, and the used of antibiotic-contaminated water for crop irrigation leads to plant exposure to these chemicals. ${ }^{2}$ In addition, the use of animal excrement as plant fertilizer is also a source of antibiotics for plants. ${ }^{3}$

*e-mail: debora@vet.ufmg.br

"Júlio C. M. Brito and Vinícius Bernardoni contributed equally to this work. Editor handled this article: Eduardo Carasek
Concentrations of ENRO and CIPRO in soil and manure vary from $\mathrm{ug} \mathrm{kg}^{-1}$ to $\mathrm{mg} \mathrm{kg}^{-1}$, according to the species and application area. ${ }^{4-11}$ Plants are able to uptake and accumulate antibiotics from their growth substrate ${ }^{3}$ and the presence of antibiotic residues in plants has been associated with the spread of antibiotic resistance in microorganisms. ${ }^{12}$

In addition to contribute to their insertion into food web, the contamination of plants with antibiotic residues from soil and water has detrimental effects on plant physiology, ${ }^{13,14}$ with CIPRO and ENRO (which can be metabolized by the plant to yield CIPRO) being representative antibiotics. ${ }^{1,3}$ These residues accumulate in plant tissues, inducing oxidative stress and increasing the production of hydrogen peroxide, thereby interfering with the plant's photosynthesis system and compromising its development. ${ }^{11,13}$

Maize is an important cultivar worldwide owing to its major contribution to both human and animal diets, 
and is therefore an important raw material for the food industry. ${ }^{15-17}$ As a result, the presence of contaminants that compromise the development of maize is undesirable because they result in reduced production and damage to the crop. For example, in maize, CIPRO residues have a significant inhibitory effect on the plant height, root length, net photosynthesis rate, stomatal conductance, transpiration rate, and dry weight of the stem, leaf, and grain. ${ }^{18}$ Moreover, accumulation of ENRO and CIPRO by maize plants was observed $^{2,19}$ alerting to the insertion of these antibiotics in human and animal diet.

The availability of techniques for quantifying antibiotic residues, particularly fluoroquinolones, is important in the study of maize development in which irrigation by water or exposure to soil or fertilizers can lead to contamination by such compounds. ${ }^{15-17}$ In addition, owing to the economic importance of crops such as maize, the development of validated methods for detecting these residues in their matrices has received particular attention. ${ }^{20-22}$

Method validation is a key element in the establishment of reference methods and in the assessment of a laboratory's competence in producing reliable analytical data. ${ }^{23}$ Hence, the scope of the term "method validation" is broad, especially if one considers the role of quality assurance/ quality control (QA/QC) validation of analytical methods and laboratory procedures for chemical measurements. ${ }^{20}$

Although a number of studies have been published evaluating the presence and levels of CIPRO and ENRO in plants, the majority of these studies were based on non-validated methods, which compromises the reliability of the results. ${ }^{11,12,18,19}$ Moreover, although some methods exist for the analyses of CIPRO and ENRO residues, no such validated method is available for their determination in the shoot segments of maize.

Therefore, we herein report the validation of a highperformance liquid chromatography method coupled to fluorescence detection (HPLC-FLD) for the determination of ENRO and CIPRO in maize crops, which could ultimately be used for monitoring CIPRO and ENRO in other cultivars.

\section{Experimental}

\section{Chemicals and reagents}

The ciprofloxacin standard (USP, 99.0\%) and the enrofloxacin standard $(99.8 \%)$ were obtained from SigmaAldrich, MO, USA. The following other reagents were also employed: sodium hydroxide (Neon, São Paulo, Brazil), dibasic sodium phosphate (Neon, São Paulo, Brazil), monobasic sodium phosphate (Cromoline-Química Fina,
São Paulo, Brazil), phosphoric acid (Sigma-Aldrich, St. Louis, USA), triethylamine (Merck, Darmstadt, Germany), methanol (Merck, Darmstadt, Germany), acetonitrile (Honeywell, USA), and chloroform (Chemical CRQ, São Paulo, Brazil). All reagents used were of pro analysis (p.a.) grade, except the solvents used in HPLC, which were of high-performance liquid chromatography (HPLC) or higher grade.

\section{Standard solutions}

The CIPRO and ENRO standards were initially diluted in a mixture of $0.1 \mathrm{~mol} \mathrm{~L}^{-1}$ aqueous sodium hydroxide, methanol, and water (40:40:20, v/v/v), and subsequent dilutions were carried out using a mixture of $0.4 \%$ triethylamine, methanol, and acetonitrile $(80: 12: 8, \mathrm{v} / \mathrm{v} / \mathrm{v})$. The final concentrations obtained were $30,40,50,60,70$ and $100 \mu \mathrm{g} \mathrm{kg}^{-1}$, and all solutions were stored in amber flasks at $-20{ }^{\circ} \mathrm{C}$ following their preparation.

\section{Extraction procedure}

The blank samples of Zea mays used for validation were grown in the Universidade Federal do Paraná (UFPR) garden using soil that was free from quinolones. All samples were collected 30 days after planting. The roots were removed from the samples and the shoot were milled. The ground cultivars $(0.5 \mathrm{~g})$ were weighed into $15 \mathrm{~mL}$ polypropylene tubes and stored in a freezer at $-20^{\circ} \mathrm{C}$ until required for analysis.

The extraction methodology employed herein was based on a procedure described by Migliore $e t$ al. ${ }^{3}$ with some modifications. Each ground sample $(0.5 \mathrm{~g})$ was weighed into a centrifugation tube equipped with a lid and homogenized. Following the subsequent addition of the CIPRO and ENRO standards, the mixtures were allowed to stand for $10 \mathrm{~min}$ at $25^{\circ} \mathrm{C}$ prior to extraction with acetonitrile/acetic acid (99:1, $1.5 \mathrm{~mL}$ ), and then vortexed for $1 \mathrm{~min}$, and sonicated for $5 \mathrm{~min}$. Then, the obtained extract was dried in a vacuum concentrator. Subsequently, an aliquot $(2 \mathrm{~mL})$ of saline phosphate buffer ( 0.2 or $\left.0.5 \mathrm{~mol} \mathrm{~L}^{-1}, \mathrm{pH} 7\right)$ was added, and the mixture was vortexed for $30 \mathrm{~s}$. Chloroform $(5 \mathrm{~mL})$ was then added, the mixture was stirred for $2.5 \mathrm{~min}$, sonicated for $5 \mathrm{~min}$, centrifuged at $4,000 \mathrm{rpm}$ for $5 \mathrm{~min}$. Then, $3 \mathrm{~mL}$ of the organic phase (chloroform) was collected and dried in a vacuum concentrator. The obtained extract was resuspended with a mixture $(1 \mathrm{~mL})$ of $0.4 \%$ trimethylamine solution at $\mathrm{pH} 3.0$, methanol, and acetonitrile $(80: 12: 8, \mathrm{v} / \mathrm{v} / \mathrm{v})$, vortexed for $30 \mathrm{~s}$, sonicated for $5 \mathrm{~min}$, and filtered through a filter unit with nylon membrane (pore size $0.22 \mu \mathrm{m}$, diameter of $13 \mathrm{~mm}$ ). 


\section{Chromatographic conditions}

An HPLC system (Alliance Waters) equipped with a controller (Waters 2695 separations module) and a fluorescence detector (Waters 2475) was used for analysis. The analyte was separated using a Supelco Analytical Ascentis C18 column $(250 \times 4.6 \mathrm{~mm}, 5 \mu \mathrm{m})$ at $35^{\circ} \mathrm{C}$ with a flow rate of $1 \mathrm{~mL} \mathrm{~min}{ }^{-1}$ and a sample injection volume of $20 \mu \mathrm{L}$. Excitation and emission wavelengths of 278 and $453 \mathrm{~nm}$, respectively, were used. The mobile phase consisted of a $0.4 \%$ triethylamine solution at pH 3.0 (mobile phase A), methanol (mobile phase B), and acetonitrile (mobile phase $\mathrm{C}$ ), and the gradient elution program followed is outlined in Table 1.

Table 1. HPLC mobile phase elution gradient program

\begin{tabular}{lccc}
\hline time / min & $\begin{array}{c}\text { Mobile } \\
\text { phase A / \% }\end{array}$ & $\begin{array}{c}\text { Mobile } \\
\text { phase B / \% }\end{array}$ & $\begin{array}{c}\text { Mobile } \\
\text { phase C / \% }\end{array}$ \\
\hline 0 & 80 & 12 & 8 \\
5 & 80 & 12 & 8 \\
8 & 78 & 13 & 9 \\
12 & 76 & 14 & 10 \\
18 & 5 & 95 & 0 \\
21 & 5 & 95 & 0 \\
25 & 80 & 12 & 8 \\
\hline
\end{tabular}

\section{Validation procedures}

For method validation, the linearity, matrix effect, precision, accuracy, limits of quantification (LOQ) and detection (LOD), and robustness were evaluated.

The linearity of the method was evaluated by the analysis of blank samples that were spiked with standard solutions of CIPRO and ENRO at five concentrations (30, 40, 50, 70, and $\left.100 \mu \mathrm{g} \mathrm{kg}^{-1}\right)$ in triplicate. From the obtained chromatograms, the peak absorption band areas were integrated and calibration curves were created, which allowed the determination coefficients $\left(\mathrm{R}^{2}\right)$ and correlation coefficients (r) to be obtained for the blank (i.e., without antibiotics) and fortified samples. The matrix-matched calibration curves obtained for CIPRO and ENRO were analyzed for the normal distribution of residues according to the Ryan-Joine test, while self-correlation was examined using the Durbin-Watson test; the residue homogeneity was determined by the Brown-Forsythe test, and the linearity was obtained by analysis of variance (ANOVA). ${ }^{24,25}$

The method selectivity was evaluated by analysis of the chromatograms of the blank samples to verify the presence of interferences that may elute at the same retention time as the target analytes.
The matrix effect was evaluated using two calibration curves: one obtained using the fortified matrix extracts and the other containing no matrix (i.e., standard solutions of the analytes of interest) at five different concentrations (30, 40, 50, 70, and $100 \mu \mathrm{g} \mathrm{kg}^{-1}$ ). After reconstitution of the matrix extracts, the standard solution containing the analytes of interest was added, and the mixture was vortexed for $30 \mathrm{~s}$. Then, the samples were injected and the curves were analyzed in triplicate at each concentration level, and the $F$-test and $t$-test at $95 \%$ significance were used to evaluate the variance and means between the slopes of the calibration curves. ${ }^{20,24,25}$

The precision of the method was assessed in terms of its repeatability and its within-laboratory reproducibility. To evaluate the repeatability, blank samples were spiked at concentrations of 30,60 , and $100 \mu \mathrm{g} \mathrm{kg}^{-1}$ and analyzed in triplicate under the same operating conditions established for the method; the same instrumentation setup was also used, and the same analyst carried out the measurements. ${ }^{20,24,25}$ Analysis of the within-laboratory reproducibility employed the same protocol, although in this case, the analyses were performed on different days and by two different operators. The relative standard deviation (RSD) was assessed considering the criteria established by the Analytical Quality Assurance Manual. ${ }^{24}$

The accuracy of the method was evaluated by recovery tests. Blank samples were spiked at three different concentrations $\left(30,60\right.$, and $\left.100 \mu \mathrm{g} \mathrm{kg}^{-1}\right)$ and were analyzed in triplicate. ${ }^{20,24}$ The recovery was calculated using the following equation:

Recovery $(\%)=($ measured content/fortification level $) \times$ 100

and the obtained values were assessed based on the acceptance criteria established by the Analytical Quality Assurance Manual. ${ }^{24}$

To determine the LOD and LOQ, a method based on analysis of the standard deviation of the response $(\sigma)$ and the slope of the analytical curve (s) was used. ${ }^{26}$ Thus, two equations were used to calculate these parameters:

$\mathrm{LOD}=[(3.3 \times \sigma) / \mathrm{s}]$

$\mathrm{LOQ}=[(10 \times \sigma) / \mathrm{s}]$

The robustness of the method was evaluated using Youden's J statistic ${ }^{27}$ with small, pre-established changes in the chromatographic conditions. The nominal values of the method were represented by capital letters (A, B, and $\mathrm{C}$ ), while the corresponding lower-case letters (a, b, and c) denoted the alternative values (Table 2). Eight runs of 
blank samples, fortified at $60 \mu \mathrm{g} \mathrm{kg}$, were carried out in duplicate to determine the influence of each factor on the final result. The standard deviation of the within-laboratory reproducibility $\left(\mathrm{s}_{\mathrm{repro}}\right)$ was compared with the standard deviation of the difference of factors $\left(\mathrm{s}_{\text {factor }}\right)$, and when $\mathrm{s}_{\text {factor }}>\mathrm{s}_{\text {repro }}$, the method was considered to be not robust.

Table 2. Parameters evaluated for determining the method robustness

\begin{tabular}{lllllllll}
\hline Factor & 1 & 2 & 3 & 4 & 5 & 6 & 7 & 8 \\
\hline A or a & A & A & A & A & a & a & a & a \\
B or b & B & b & B & b & B & b & B & b \\
C or c & C & C & c & c & C & C & c & c \\
\hline
\end{tabular}

A: phosphate buffer solution $0.5 \mathrm{~mol} \mathrm{~L}^{-1}$; a: phosphate buffer solution $0.2 \mathrm{~mol} \mathrm{~L}^{-1}$; B: column temperature $35^{\circ} \mathrm{C}$; b: column temperature $28^{\circ} \mathrm{C}$; $\mathrm{C}$ : vortex shaking time $2.5 \mathrm{~min}$; c: vortex shaking time $1 \mathrm{~min}$.

\section{Results and Discussion}

The quantification of residues in plants is somewhat complex, and so the development of a suitable extraction procedure is necessary to remove the analytes from the interiors of the plant cells without significant contamination by other components or interferants. For the method reported here, control of the extraction $\mathrm{pH}$ using a buffer was found to be essential, with a pH of 7 being optimal. At $\mathrm{pH}$ values below 6 or above 8, both CIPRO and ENRO exhibited a greater affinity for polar solvents ${ }^{28}$ thereby compromising the chloroform extraction procedure.

It was found that for the analyses of both antibiotics, our method showed linearity in the concentration range of 30 to $100 \mu \mathrm{g} \mathrm{kg}^{-1}$, with $\mathrm{R}^{2}$ values of 0.9907 for CIPRO and 0.9962 for ENRO (Table 3). It should also be noted that the latter exhibited an angular coefficient seven times greater than that of CIPRO, indicating that ENRO emits a greater signal than CIPRO in the matrix medium. The values obtained are within the range recommended by Agência Nacional de Vigilância Sanitária (ANVISA) $(>0.99) .{ }^{25}$ In addition, in the linearity study, it was found that both quinolones followed the normal distribution of the residues, irrespective of the residue, and both were homoscedastic, with no deviation in linearity.

As mentioned previously, the selectivity was determined using the chromatograms obtained for the blank matrix,

Table 3. Linearity data of the method used for the determination of ciprofloxacin (CIPRO) and enrofloxacin (ENRO) in maize (analyte concentration range: $30-100 \mu \mathrm{g} \mathrm{kg}^{-1}$ )

\begin{tabular}{lccc}
\hline Analyte & Equation & $\mathrm{R}^{2}$ & $\mathrm{r}$ \\
\hline CIPRO & $y=0.0104 x-0.0264$ & 0.9907 & 0.9953 \\
ENRO & $y=0.0755 x-0.4064$ & 0.9962 & 0.9980 \\
\hline
\end{tabular}

$\mathrm{R}^{2}$ : coefficient of determination; $\mathrm{r}$ : correlation coefficient. the solvent standards, and the matrix pattern, as shown in Figure 1. It can be seen that around the retention times of the two antibiotics, i.e., between 10 and $15 \mathrm{~min}$, no absorption bands corresponding to other substances were observed. This confirms that the employed extraction procedure was efficient and that the analytic method had been successfully optimized.
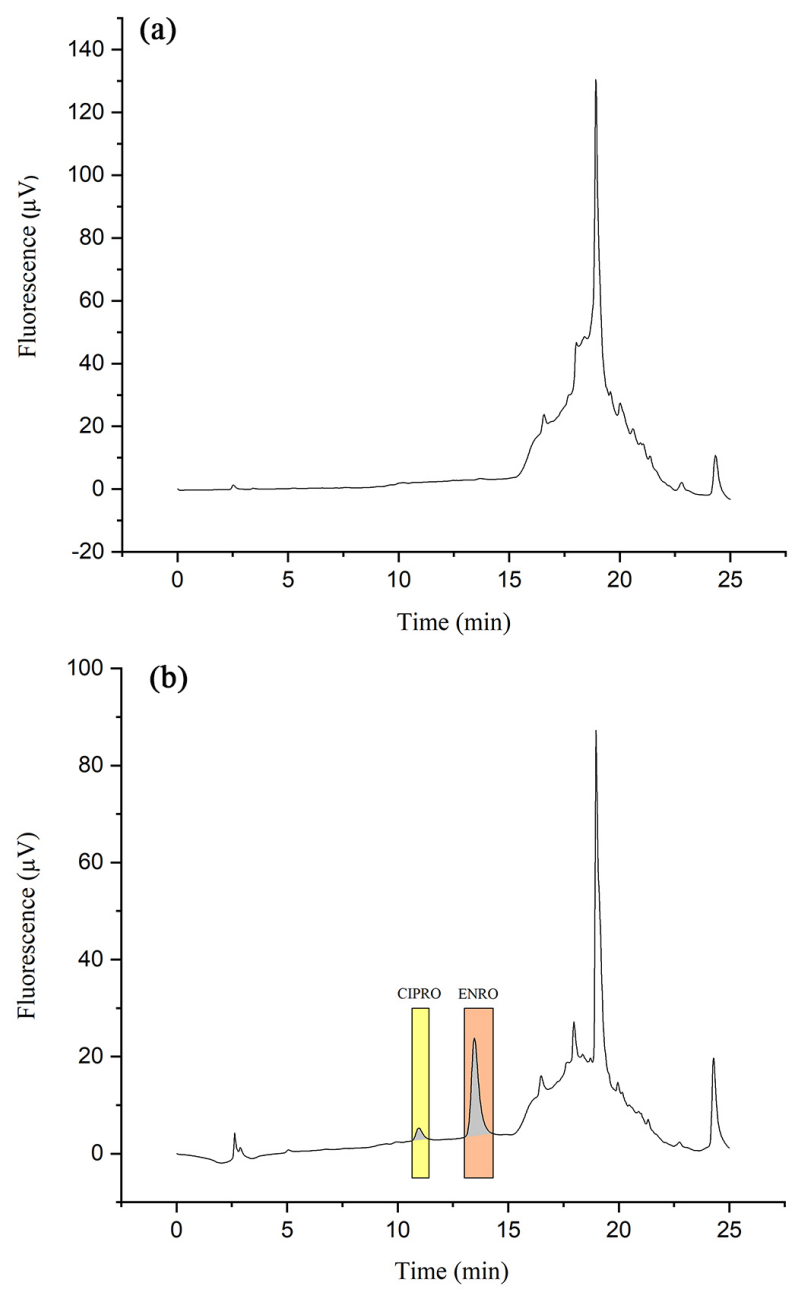

Figure 1. Chromatograms of (a) the maize free of the ciprofloxacin and enrofloxacin (blank samples), and (b) the maize samples spiked with ciprofloxacin and enrofloxacin at analyte concentrations of $100 \mu \mathrm{g} \mathrm{kg}^{-1}$.

During evaluation of the matrix effects, significant differences were found between the slopes of the calibration curves obtained for CIPRO and ENRO for both the standards in solution and the matrix-containing samples (Figure 2). As can be seen in the figure, over all concentration points for both residues, the matrix curve differs from the solvent curve both in terms of the absorption value and in its slope, although the effects were more pronounced in the case of CIPRO. The $F$-test and $t$-test were then performed to evaluate the variance and means between the slopes of the calibration curves, and it was found that a significant matrix effect 
Table 4. Recoveries (REC) and relative standard deviations (RSDs) obtained during the validation experiments at concentrations of 30,60 , and $100 \mu \mathrm{g} \mathrm{kg}^{-1}$

\begin{tabular}{|c|c|c|c|c|c|c|c|c|c|}
\hline \multirow{2}{*}{ Analyte } & \multicolumn{3}{|c|}{ REC / \% } & \multicolumn{3}{|c|}{ RSD repeat / \% } & \multicolumn{3}{|c|}{ RSD repro / \% } \\
\hline & $30 \mu \mathrm{g} \mathrm{kg}^{-1}$ & $60 \mu \mathrm{g} \mathrm{kg}^{-1}$ & $100 \mu \mathrm{g} \mathrm{kg}^{-1}$ & $30 \mu \mathrm{g} \mathrm{kg}^{-1}$ & $60 \mu \mathrm{g} \mathrm{kg}^{-1}$ & $100 \mu \mathrm{g} \mathrm{kg}^{-1}$ & $30 \mu \mathrm{g} \mathrm{kg}^{-1}$ & $60 \mu \mathrm{g} \mathrm{kg}^{-1}$ & $100 \mu \mathrm{g} \mathrm{kg}^{-1}$ \\
\hline CIPRO & 90.78 & 105.05 & 86.49 & 5.24 & 11.83 & 6.46 & 11.73 & 9.04 & 4.32 \\
\hline ENRO & 123.1 & 110.24 & 108.28 & 3.75 & 3.73 & 4.64 & 9.35 & 8.06 & 3.82 \\
\hline
\end{tabular}

CIPRO: ciprofloxacin; ENRO: enrofloxacin; REC: recovery; RSD repeat: relative standard deviation obtained under repeatability conditions; RSD repro: relative standard deviation obtained under within-laboratory reproducibility conditions.

existed ${ }^{24}$ confirming the visual observations. When working with complex matrices that contain low concentrations of the analytes of interest, evaluation of the matrix effect is of great importance to avoid erroneous results. ${ }^{26,29}$

\section{Enrofloxacin}

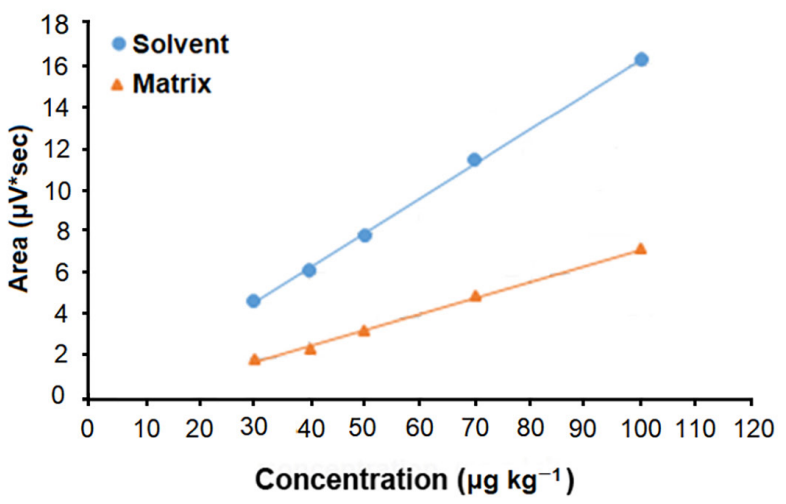

\section{Ciprofloxacin}

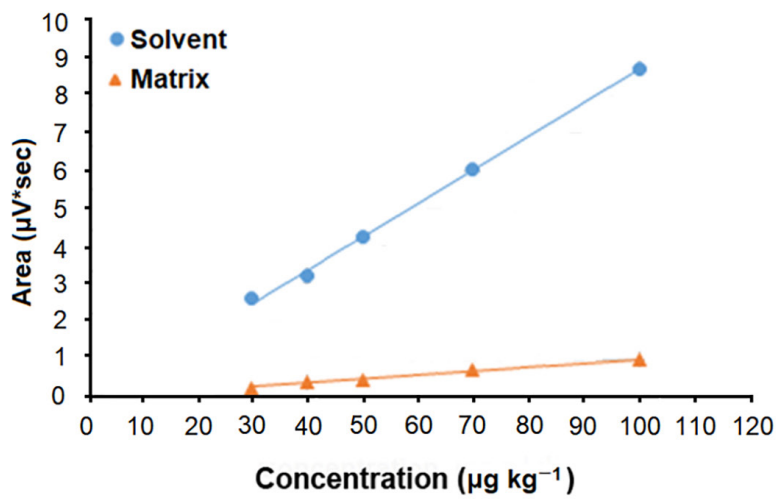

Figure 2. Matrix effects in the determination of ciprofloxacin and enrofloxacin in maize.

The precision of the method was then evaluated using a series of measurements carried out on multiple aliquots of the same homogeneous sample under predetermined conditions, and the $\operatorname{RSDs}^{29}$ of the measurements were then calculated, as outlined in Table 4. Based on the obtained results, this method was confirmed to be accurate, since the Analytical Quality Assurance Manual ${ }^{24}$ recommends that a method is determined to be accurate when the RSD is $\leq 20 \%$.
The accuracy of a method is defined as the agreement between the real value of the analyte in the sample and that estimated by the analytical process; ${ }^{24,30}$ the values obtained for this method varied between 86.49 and $123.1 \%$ (Table 4). According to RDC No. $166,{ }^{25}$ which is used to establish accuracy with a uniform content, the variation in recovery should range between 70 and $130 \%$, and therefore, our method was accurate within the analytical parameters defined above for concentrations of 30,60 , and $100 \mu \mathrm{g} \mathrm{kg}^{-1}$.

The LOD is the smallest amount of an analyte that can be detected in a sample and is not necessarily quantifiable as an exact value. In contrast, the LOQ is the smallest amount of an analyte that can be quantified with precision and accuracy in a given sample. ${ }^{24}$ The LOD and LOQ were determined for our method, and the results are presented in Table 5. As can be seen, the LOD and LOQ for CIPRO were approximately three times higher than those of ENRO.

Table 5. Limits of detection (LOD) and limits of quantification (LOQ)

\begin{tabular}{lcc}
\hline Analyte & $\mathrm{LOD} /\left(\mu \mathrm{g} \mathrm{kg}^{-1}\right)$ & $\mathrm{LOQ} /\left(\mu \mathrm{g} \mathrm{kg}^{-1}\right)$ \\
\hline CIPRO & 16.65 & 50.44 \\
ENRO & 6.57 & 19.92 \\
\hline
\end{tabular}

CIPRO: ciprofloxacin; ENRO: enrofloxacin.

Previous studies have reported high concentrations of CIPRO and ENRO in soil and manure. CIPRO and ENRO were found at concentrations between $0.65-2.13 \mathrm{mg} \mathrm{kg}^{-1}$ and $0.39-30 \mathrm{mg} \mathrm{kg}^{-1}$ in poultry litter, respectively, whereas 17.36-26.65 $\mu \mathrm{g} \mathrm{kg}^{-1}$ of ENRO were found in soil. ${ }^{7}$ The presence of ENRO and CIPRO in maize cultivated in soil irrigated with enrofloxacin-contaminated water $\left(10 \mu \mathrm{g} \mathrm{L}{ }^{-1}\right)$ was reported by Marques et al. ${ }^{2}$ CIPRO and ENRO were found in the leaves at concentrations of approximately 18 and $75 \mu \mathrm{g} \mathrm{kg}{ }^{-1}$, respectively, ${ }^{2}$ demonstrating the adequacy of the method for the detection and quantification of these antibiotics in maize.

Finally, analysis of the method robustness for CIPRO and ENRO showed that this method did not demonstrate robustness upon variation in the phosphate buffer concentration, the column temperature, or the vortex/agitation time, since the standard deviation of the 
difference of factors $\left(\mathrm{s}_{\text {factor }}\right)$ was higher than the standard deviation of the within-laboratory reproducibility $\left(\mathrm{s}_{\text {repro }}\right)$. Therefore, these factors must be strictly controlled during the analysis.

\section{Conclusions}

Owing to the lack of validated analytical methods for the analyses of CIPRO and ENRO in the shoot of Zea mays maize, we developed and validated a reversed-phase HPLC-FLD method for this purpose. Using this validated method rendered it is possible to detect and investigate the residues of ciprofloxacin and enrofloxacin present in the maize samples, and low concentrations of the studied analytes could be detected and quantified. It should also be noted that all validation parameters were in accordance with the requirements of Brazilian law. This method is beneficial since it is rapid, uses a simple sample preparation procedure without the need for dilution, and is low cost. Overall, the developed analytical method can be considered a reliable and useful tool for the analysis of ciprofloxacin and enrofloxacin in the shoot of maize.

\section{Acknowledgments}

The authors acknowledge the Fundação Ezequiel Dias (FUNED) for providing the infrastructure and supplies for this study, and the assistance of the Postgraduate Collegiate in Animal Science at the Universidade Federal de Minas Gerais (UFMG) for providing funds for the publication of the article.

The authors also thank the Conselho Nacional de Desenvolvimento Científico e Tecnológico (CNPq) for providing a productivity fellowship (Marcelo P. Gomes) and funds for research (Debora C. S. de Assis, APQ 426422/2018-0).

\section{Author Contributions}

Júlio C. M. Brito was responsible for conceptualization, data curation, formal analysis, investigation, project administration, methodology, software, validation, visualization, and writing original draft; Vinícius Bernardoni for conceptualization, data curation, formal analysis, investigation, project administration, methodology, software, validation, visualization, and writing original draft; Thais M. L. da Silva for conceptualization, data curation, formal analysis, investigation, project administration, methodology, software, validation, visualization, and writing original draft; Laurenice S. X. S. Ramos for methodology, formal analysis, investigation, validation, visualization; Marcelo R. Pedrosa for conceptualization, resources, visualization, methodology, writing-review and editing; Débora C. S. de Assis conceptualization, resources, visualization, formal analysis, validation, writing-review and editing.

\section{References}

1. Tasho, R. P.; Cho, J. Y.; Sci. Total Environ. 2016, 563-564, 366.

2. Marques, R. Z.; Wistuba, N.; Brito, J. C. M.; Bernardoni, V.; Rocha, D. C.; Gomes, M. P.; Ecotoxicol. Environ. Saf. 2021, 216, 112193.

3. Migliore, L.; Cozzolino, S.; Fiori, M.; Chemosphere 2003, 52, 1233.

4. Martínez-Carballo, E.; González-Barreiro, C.; Scharf, S.; Gans, O.; Environ. Pollut. (Oxford, U. K.) 2007, 148, 570.

5. Karci, A.; Balcioğlu, I. A.; Sci. Total Environ. 2009, 407, 4652.

6. Li, Y.; Wu, X.; Mo, C.; Tai, Y.; Huang, X.; Xiang, L.; J. Agric. Food Chem. 2011, 59, 7268.

7. Leal, R. M. P.; Figueira, R. F.; Tornisielo, V. L.; Regitano, J. B.; Sci. Total Environ. 2012, 432, 344.

8. Li, X.-W.; Xie, Y.-F.; Li, C.-L.; Zhao, H.-N.; Zhao, H.; Wang, N.; Wang, J.-F.; Sci. Total Environ. 2014, 468-469, 258.

9. Li, C.; Chen, J.; Wang, J.; Ma, Z.; Han, P.; Luan, Y.; Lu, A.; Sci. Total Environ. 2015, 521-522, 101.

10. Arun, S.; MohanKumar, R.; Ruppa, J.; Mukhopadhyay, M.; Ilango, K.; Chakraborty, P.; Environ. Toxicol. Pharmacol. 2020, 79, 103410 .

11. American Society for Microbiology Plants; Not Just AntibioticFed Poultry and Livestock - May be Transmitting Superbugs to People, ASM Press Release, 2019, available at https://asm. org/Press-Releases/2019/June/Plants-Not-Just-Antibiotic-FedPoultry-and-Lives, accessed in September 2021.

12. Gomes, M. P.; Gonçalves, C. A.; Brito, J. C. M.; Souza, A. M.; da Silva Cruz, F. V.; Bicalho, E. M.; Figueredo, C. C.; Garcia, Q. S.; J. Hazard. Mater. 2017, 328, 140.

13. Gomes, M. P.; Richardi, V. S.; Bicalho, E. M.; da Rocha, D. C.; Navarro-Silva, M. A.; Soffiatti, P.; Garcia, Q. S.; Sant'AnnaSantos, B. F.; Sci. Total Environ. 2019, 767, 144902.

14. Jones, P.; Thornton, P.; Global Environ. Change 2003, 13, 51.

16. Ranum, P.; Peña-Rosas, J. P.; Garcia-Casal, M. N.; Ann. N.Y. Acad. Sci. 2014, 1312, 105.

17. Katz, S. H.; Hediger, M. L.; Valleroy, L. A.; Science 1974, 184, 765 .

18. Junmei, Q.; Huaye, X.; J. Shanxi Agric. Univ., Nat. Sci. Ed. 2017, 37, 77.

19. Gomes, M. P.; Rocha, D. C.; Moreira de Brito, J. C.; Tavares, D. S.; Marques, R. Z.; Soffiatti, P.; Sant'Anna-Santos, B. F.; Ecotoxicol. Environ. Saf. 2020, 196, 110549.

20. van Zoonen, P.; Klooster, H. A. V.; Hoogerbrugge, S. M. G.; van de Wiel, H. J.; Arh. Hig. Rada Toksikol. 1998, 49, 355.

21. Shabir, G. A.; J. Chromatogr. A 2003, 987, 57.

22. Chandran, S.; Singh, R. S.; Pharmazie 2007, 62, 4. 
23. Hund, E.; Massart, D. L.; Smeyers-Verbeke, J.; Anal. Chim. Acta 2000, 423, 145.

24. Ministério da Agricultura Pecuária e Abastecimento (MAPA); Manual de Garantia da Qualidade Analítica, 2015, available at https://www.gov.br/agricultura/pt-br/assuntos/inspecao/ produtos-vegetal/legislacao-1/biblioteca-de-normas-vinhos-ebebidas/manual-de-garantia-da-qualidade-analitica_2015.pdf, accessed in September 2021.

25. Agência Nacional de Vigilância Sanitária (ANVISA); Resolução da Diretoria Colegiada (RDC) No. 166, Dispõe sobre A Validação de Métodos Analíticos e dá outras Providências; Diário Oficial da União (DOU), Brasília, No. 141, de 25/07/2017, available at http://antigo.anvisa.gov.br/documents/10181/2721567/ RDC_166_2017_COMP.pdf/d5fb92b3-6c6b-4130-86704e3263763401\#: :text=Disp\%C3\%B5e\%20sobre\%20a\%20 valida\%C3\%A7\%C3\%A3o\%20de,de\%201999\%2C\%20e\%20 ao\%20art, accessed in September 2021.
26. Bhaskaran, N. A.; Kumar, L.; Reddy, M. S.; Pai, G. K.; Acta Pharm. 2021, 71, 57.

27. Youden, W. J.; Steiner, E. H.; Statistical Manual of the AOACAssociation of the Official Analytical Chemists; AOAC-I Washington DC, 1975, available at https://members.aoac.org/ ItemDetail?iProductCode $=12050 \&$ Category $=$ BOOK $\&$ Websit eKey=2e25ab5a-1f6d-4d78-a498-19b9763d11b4, accessed in September 2021

28. Jalil, M. E. R.; Baschini, M.; Sapag, K.; Appl. Clay Sci. 2015, $114,69$.

29. González, A. G.; Herrador, M. A.; TrAC, Trends Anal. Chem. 2007, 26, 227.

30. Francotte, E.; Davatz, A.; Richert, P.; J. Chromatogr. B: Anal. Technol. Biomed. Life Sci. 1996, 686, 77.

Submitted: July 1, 2021

Published online: September 15, 2021 